https://helda.helsinki.fi

\title{
Professional role enactment amid information warfare : War correspondents tweeting on the Ukraine conflict
}

\section{Ojala, Markus Mikael}

2018-03-01

Ojala , M M , Pantti , M K \& Kangas , J 2018 , ' Professional role enactment amid information warfare : War correspondents tweeting on the Ukraine conflict ' , Journalism , vol. 19 , no. 3 , pp. 297-313 . https://doi.org/10.1177/1464884916671158

http://hdl.handle.net/10138/233476

https://doi.org/10.1177/1464884916671158

acceptedVersion

Downloaded from Helda, University of Helsinki institutional repository.

This is an electronic reprint of the original article.

This reprint may differ from the original in pagination and typographic detail.

Please cite the original version. 
This is a revised article manuscript whose final and definitive version has been published in Journalism, 26 September 2016. The published article is available online at https://doi.org/10.1177/1464884916671158

\title{
Professional Role Enactment Amidst Information Warfare War correspondents tweeting on the Ukraine conflict
}

\author{
Markus Ojala, University of Helsinki, Finland \\ Mervi Pantti, University of Helsinki, Finland \\ Jarkko Kangas, University of Tampere, Finland
}

\begin{abstract}
War correspondents work within a networked media environment characterised not only by an explosion of information but also a wide range of actors producing competing narratives and viewpoints. This study examines the ways in which war correspondents enact their professional roles when tweeting from within a conflict zone. The analysis sheds light on the conditions of modern information warfare in the context of reporting from within the Ukraine conflict. It also identifies the emerging social media practices of war correspondents and the different role categories that journalists are adopting on Twitter.
\end{abstract}

\section{Keywords}

War correspondents, information war, professional roles, role enactment, Twitter, Ukraine conflict

\section{Introduction}

In the context of modern conflicts and wars, Twitter features as a boundless news environment in which facts, eyewitness accounts and viewpoints can be disseminated, verified and contested by a wide range of actors. Undermining its inherently pluralising and democratising character, the platform also turns into a hotbed of disinformation and confrontation as conflicting parties attempt 
to mobilise support and discredit their adversaries. In circumstances in which digital media have been effectively subverted to propaganda purposes, as has been the case in the on-going Ukraine conflict (Hoskins and O'Loughlin, 2015; Boyd-Barrett, 2015), news professionals become unavoidably entangled within information warfare regarding the definition of the conflict (cf. Siapera et al., 2015). Therefore, it is important to understand how war correspondents - as the key mediators between the public and the conflict - deal with contemporary information war and how it might affect the enactment of their professional roles.

The relationship between new media technologies and changes in journalistic practices and styles figures prominently in journalism scholarship. While there is a rapidly growing number of studies concentrating on how news organisations and professional journalists use Twitter as a journalistic tool and how it may change journalistic norms and daily practices (e.g. Canter, 2015; Hermida, 2013; Lasorsa et al., 2012; Lawrence et al., 2013; Revers, 2015), hardly any attention has been paid to war correspondents' use of Twitter. Changes in both the information environment and in modern warfare are mounting new pressures on reporters in conflict zones and may influence their practices and journalistic production, or the ways in which they conceive of and enact their role as journalists.

Drawing on research on the journalistic uses of Twitter, journalistic roles and conflict reporting, this study examines the ways in which Finnish war correspondents enact their professional roles when tweeting about the Ukraine conflict. Foreign correspondents use Twitter as a reporting tool but, at the same time, they also present and define themselves as journalists on the platform. Accordingly, we argue that by studying correspondents' tweets we can further our knowledge of the specific challenges of journalistic work in conflict zones and discover more about the role that war correspondents enact in contested information environments.

In the next two sections, we provide a brief overview of modern information warfare in the new media ecosystem and discuss previous studies on how journalists use Twitter, as well as the implications for how journalists enact their role. This is followed by a description of the data collection methods and analysis used in our research. We then provide an overview of our findings, presenting four distinct roles that are performed by correspondents when tweeting on the Ukraine conflict. We conclude with a discussion of the ways in which Twitter may shape the traditional roles of journalists covering international conflicts. 


\section{Twitter as an arena for conflict}

Since early 2014, the political crisis in Ukraine has evolved into a prolonged international conflict and a military confrontation that has claimed over 9,000 casualties and internally displaced over 1.6 million Ukrainians (European Commission, 2016). Perceptions differ on whether the military dimension of the conflict should be regarded as primarily a civil war between the central government and separatist insurgents in the eastern Ukraine, a war between Ukraine and Russia, or a de facto 'proxy war' between Russia and the West locked in mutual animosity (e.g. Ishchenko, 2014; Motyl, 2015; Pikulicka-Wilczewska and Sakwa, 2015; Sakwa, 2015; Wilson, 2014).

What is clear, however, is that the Ukraine conflict has evolved into one of the most hotly contested 'information wars' since the end of the Cold War, with all parties claiming to be its victims (e.g. Boyd-Barrett, 2015; Galeotti, 2015; Hoskins and O’Loughlin, 2015; Snegovaya, 2015). As a consequence, the Ukraine conflict has been a particularly challenging for Western journalists: not only is reliable and impartial information scarce - as most of the relevant sources are parties to the conflict, the involvement of the United States and the EU in the conflict also poses difficult questions regarding objectivity and non-partisanship.

Efforts to control information and shape media narratives and consequently public perceptions are elementary aspects in international conflicts (McCauley, 2015; Tumber and Webster, 2006). Yet, new information technologies and social media have reshaped both the conduct and spaces of modern information warfare (Grondin, 2012; Tumber and Webster, 2006). As regards the mediated dimensions of warfare, the new media ecology not only gives rise to the multiplication of actors and sites of information management, it also enables unprecedented forms of control, deception and offense. Digital media may be particularly suitable for the conduct of information warfare due to the low cost and ease with which disinformation and propaganda can be produced and distributed globally across social networking sites (Hoskins and O'Loughlin, 2010; Kuntsman and Stein, 2015).

Twitter is among the new battlefields of information warfare in which claims of truth emerge and are critiqued. It has become integrated into military operations and harnessed for public relations campaigns during wartime (Maltby et al., 2015; Kuntsman and Stein, 2015; Siapera et al., 2015). Yet as governments and militaries launch (dis)information offensives on Twitter, they are met with counter-propaganda by the insurgents or terrorist organisations they are fighting against (e.g. Zeitzoff, 2014). The attempts of conflicting parties to control information are, in turn, undermined by the efforts of humanitarian organisations, international observers, the news media 
and media advocacy groups to provide more "truthful" accounts of the events (Khaldarova and Pantti, 2016; Omanga and Chepngetich-Omanga, 2013).

While there is a rapidly growing number of studies that concentrate on journalists' uses of Twitter, less attention has been paid to how it affects professional war reporting. Even though the Internet and social media platforms enable governments, rebel groups, NGOs and citizens alike to publish and distribute information directly and bypass journalistic gatekeeping, journalists remain key mediators between the public and the conflict's participants (Hoskins and O'Loughlin, 2011; Meraz and Papacharissi, 2013; Tumber and Webster, 2006). At the same time, correspondents' tweets from the battlefield are incorporated into Twitter's ever-evolving stream of information and shape the visibility of competing definitions and interpretations of the conflict (cf. Meraz and Papacharissi, 2013).

When using Twitter, Ukraine conflict reporters thus inevitably become entangled in the information warfare taking place on Twitter. Even as journalists' reports form a key part of the information flow on Twitter (Bruns, 2012), their work also falls under the continuous scrutiny of their audience and becomes a target of contesting truth-claims and abuse. The online attacks against journalists are related to the fact that individual reporters are better able to generate visibility than news organisations on Twitter because visibility is driven by an individual's personality (Bruns, 2012). In the context of the Ukraine crisis, both interested citizens and the 'Russian troll army' (Hoskins and O Loughlin, 2015) have employed social media to spread information and disinformation, as well as to distort and criticise news accounts, question the legitimacy of the sources cited and insult reporters. The way that conflict reporters feel the brunt of such online abuse is captured by a tweet from Shaun Walker, Moscow Correspondent for the Guardian, on 27 July 2014, a day when fighting between Ukrainian forces and pro-Russia separatists was raging in the Donetsk region and an international monitoring team was prevented from visiting the crash site of Malaysian airliner: 'My morning Twitter/email. As usual I'm Kiev whore \& Kremlin troll simultaneously. Thanks for constructive feedback!"

As all tweets from personal opinions and interpretations to eyewitness reports and retweeted links to external content may be subject to hostile commentary, correspondents need to work out practices with which to confront the efforts of interested parties in order to influence facts, evaluations and interpretations. At the same time, the public role of war correspondents - what it means to be a war correspondent and what purposes does a reporter serve in a conflict - is potentially being redefined in Twitter's contested media environment. 


\section{Professional role enactments on Twitter}

While the role and performance of journalism during wartime has been a vibrant area of study (e.g. Freedman and Thussu, 2003; Tumber and Palmer, 2004; Matheson and Allan, 2009; Zelizer and Allan, 2011), less attention has been paid to how war correspondents actually enact their roles and how these roles may be affected by changes in communication technologies, on the one hand, and modern information warfare, on the other (Kramp and Weichert, 2014; Tumber and Webster, 2006).

Journalistic roles are cultural conventions of the tasks journalists should perform in society. It is assumed that journalists internalise certain role conceptions on the basis of their perception of what news organisations, audiences, sources, key reference groups and society as a whole expect from them. Yet the personal role conceptions do not necessarily correspond with journalists' actual role enactment (Tandoc et al., 2013; Mellado and Van Dalen, 2014; Carpenter et al., 2015), which always takes place in social interaction and within a particular social context (Hellmueller and Mellado, 2015; Mellado, 2015). When covering the Ukraine conflict, the war correspondents' enactment of their journalistic role on Twitter is thus fundamentally influenced by the context of Twitter's information war and interaction with other users of the platform.

Disseminating information, interpreting events, and confronting societal powers are among the most widely studied journalistic roles (e.g. Carpenter et al., 2015; Tandoc et al., 2013). They are also the most recognised worldwide, although notable variations between countries exists concerning their relative significance (Hanitzsch et al., 2011; Hanusch and Mellado, 2014; Wilnat et al., 2013). Nevertheless, various other roles, including advocate, loyal facilitator and civic mobiliser have been identified (e.g. Carpenter et al., 2015; Mellado, 2015), and digital and social media environments have been suggested as giving rise to an even wider plurality of journalistic roles (Fahy and Nisbet, 2011). At the same time, journalists must grapple with various tensions regarding their professional roles (Kramp and Weichert, 2014). These include the adoption of a detached versus an involved role; concentrating on disseminating facts versus taking an interpretive role requiring analysis and explanation; and their role as a conduit for a variety of societal voices versus being an advocate for a chosen cause (Hanitzsch 2007; Christians et al. 2009; Tandoc et al., 2013).

The tensions regarding journalistic roles are potentially reflected in how journalists operate on Twitter. For instance, journalists have been found to struggle to balance journalistic impartiality, objectivity and accuracy against the speed, transparency and openness that social media encourage (Gulyas, 2013; Molyneux, 2015). Previous studies have noted that journalists are becoming more open to talking about their work and sharing personal life details on Twitter, and the platform also 
encourages them to express opinions and regularly use humour to maintain connections (Lasorsa et al., 2012; Holton and Lewis, 2011; Mourão, 2015). However, journalists also continue to incorporate traditional journalistic norms and roles in their use of Twitter (Hermida, 2013; Lasorsa et al., 2012). They tend to, for instance, maintain and reclaim their gatekeeping authority by selectively mentioning, retweeting, and hyperlinking content from other journalists and elite sources, rather than inviting a more open debate (Lasorsa et al., 2012; Lawrence et al., 2013; Noguera Vivo, 2013). Overall, Twitter seems to reproduce tensions in journalistic roles as the inclinations of journalists to meet the perceived expectations of their followers clashes with traditional professional norms (cf. Mourão, 2015).

\section{Material and methods}

Our qualitative analysis examines the tweeting on the Ukraine conflict made by three Finnish foreign correspondents based in Moscow. Of the three, Pekka Hakala is staff correspondent for Helsingin Sanomat, Finland's leading national daily, Anna-Lena Laurén writes for Hufvudstadsbladet, the leading Swedish-language newspaper in Finland, as well as for Svenska Dagbladet, a leading Swedish newspaper. Erkka Mikkonen reports for YLE, the Finnish public service broadcaster, which has four TV channels, several radio channels and a prominent online presence. All three correspondents frequently went to Ukraine in 2014 and 2015 to cover the key developments in the conflict. Due to their position as correspondents for leading national media institutions, they are among the most influential journalists covering the Ukraine conflict in the Finnish news. At the same time, all three correspondents work for traditional media institutions that have a culture of high professionalism and which emphasise quality in their reporting.

We observed the correspondents' tweeting practices from 12 April to 12 May 2014, a period which covers the early stages of the armed conflict in eastern Ukraine and received extensive attention from international media. The escalation of violence followed the seizing of administrative buildings and police stations by anti-government insurgents in several eastern Ukrainian cities and the announcement of a military campaign against the rebels by the interim government in Kiev which had been installed after the ousting of President Viktor Yanukovych in February. Separate incidents were reported in and close to Donetsk, Sevastopol, Mariupol, Kramatorsk and elsewhere in the region. In addition, clashes in eastern Ukraine coincided with violent riots in Odessa, where over 40 people were killed in a trade union building fire on 2 May 2014. The reasons for the failure of the Odessa police to prevent the deaths, and the involvement of the Russian government in inciting separatist insurgency, were hotly contested issues in the information warfare during this 
period. All three correspondents made at least two reporting trips from their base in Moscow to Ukraine during this period and continued to regularly tweet on the conflict in Moscow.

We collected all the tweets posted by the three correspondents during the period, which allowed us to observe differences in the tweets posted from the conflict area with those posted from the base. In total, the data consisted of 487 tweets, of which 66 were posted by Hakala, 126 by Laurén and 295 by Mikkonen. The tweets were collected with Snapbird, a free web service that allows for the retrieval of up to 3200 past tweets from a single account (cf. Vis, 2013: 30). To work out their journalistic role enactments on Twitter, we conducted a qualitative analysis of each of the three correspondents' manifest tweeting practices during the data collection period. Drawing on earlier studies of journalists on Twitter (e.g. Lasorsa et al., 2012; Molyneux, 2015; Papacharissi and de Fatima Oliveira, 2012; Vis, 2013), we concentrated not only on the formal aspects of the tweets (e.g. the use of hashtags, retweets, links to outside content, mentions of other screen names) but also on their actual argumentative content (e.g. eyewitness observation, statement, opinion, request, expression of humour). Unlike a quantitative approach employing big data sets, a close reading of the data allowed for taking into account the subtlety of opinions and interpretations that tweeters typically convey through the use of irony and sarcasm (cf. Molyneux, 2015). The smaller amount of data also allowed us to pay specific attention to the context of each individual tweet as they often exist in direct connection with other tweets. For instance, whenever a tweet was a reply to another user, we followed the link provided by Snapbird to the original tweet on Twitter, and thus observed the interaction between the correspondent and the other user(s) in its entirety.

A guiding premise in the analysis of our observations was that: on Twitter, the correspondents enact their roles not only with reference to events in the Ukraine conflict they personally witness (journalists mediating between the audience and the 'real world' of the conflict) but also with reference to the information war waged outside the actual conflict zone. In other words, Twitter is a public space in which the correspondents enact their roles by, implicitly or explicitly, taking positions with other sources of information and in interaction with other users. Accordingly, the analysis of the journalistic role enactments consisted of working out the general purpose of each of the tweets (e.g. description, interpretation, curating), the primary addressee of the tweet (e.g. general audience, own followers, specific users) and the level of personal involvement expressed (e.g. detached, involved, the opinions manifested).

In the following analysis, we focus on four main roles enacted on Twitter by the Finnish war correspondents: disseminator, interpreter, advocate and community-builder. We observe how the correspondents enact their roles in tweeting on the Ukraine conflict, paying specific attention to 
how particular tweet types and conventions are appropriate to the enactment of the roles. Moreover, the analysis illustrates how the interactive dimension of Twitter communication is a key element in the enactment of the roles, and also how the interaction brings out tensions between journalists' role enactment and the roles attributed to them by other Twitter users.

\section{Performing the role of war correspondents on Twitter}

\section{The disseminator: First-hand observations and news updates}

Twitter, and social media in general, have been said to contribute to the stretching of journalists' social space in such a way that reporters do not have to 'go out there' anymore to find information. Presenting and explaining the war and the suffering involved to their audiences truthfully is a main function of war correspondents. Journalistic claims to truth-telling are enabled by particular news practices - in which the on-site presence (eyewitnessing) is key (e.g. Carlson, 2009; Zelizer, 2007). With the proliferation of digital cameras and mobile devices, the role of the eyewitness is partly becoming 'outsourced' to citizens and other 'non-conventional journalists' with digital cameras (Zelizer, 2007: 425). However, a journalist's actual presence at a location continues to carry great significance in conflict reporting (Andén-Papadopoulos and Pantti, 2013; Cottle, 2012).

The emphasis on being a first-hand eyewitness was a key element in how the correspondents presented themselves on Twitter. The most apparent characteristic in the studied correspondents' use of Twitter was the notable increase in the amount of first-hand observations about their immediate surroundings, compared to their tweeting from outside the conflict zone. Eyewitness tweets mostly consisted of descriptions of the witnessed actions and emotions of the people present at a scene. Of the three correspondents, Erkka Mikkonen was the most active tweeter of first-hand observations, typically describing events in the present tense and tweeting several minute-by-minute updates from a scene: 'Hundreds of pro-Ukrainians marching in central \#Odessa towards ministry of the interior. Many have bats and helmets' (4 May 2014, 11:29am); 'Shouting "Odessa is part of Ukraine!' (4 May 2014, 11:30am). The correspondents frequently complemented their verbal eyewitness reporting by posting their own photos of the scenes they were covering. As the photos were typically used to illustrate or corroborate the tweeted observations, they functioned as further claims of 'being there' and reinforcing reporters' credibility (cf. Butler, 2005: 824; Zelizer, 2007: 418). 
While very prominent, eyewitnessing was not the only way for the correspondents to enact the role of disseminator on Twitter. They also posted tweets and retweets with the purpose of reporting on important developments in the Ukraine conflict, typically concerning the actions or statements of the parties involved. These were particularly significant ways of disseminating information when the correspondents were in Moscow, away from the actual scene of the conflict. Often these news update tweets and retweets included a headline and a link to an online news report. Laurén and Mikkonen were also active in linking to their own reports, whereas Hakala refrained from promoting his own work. The sharing of one's own articles on Twitter has often been identified as a form of self-promotion (e.g. Canter, 2015; Lasorsa et al., 2012; Molyneux, 2015), and this was evident especially in Mikkonen's tendency to retweet other users' links to online news stories that featured himself as reporter or eyewitness. Yet, even as elements of selfpromotion have seeped into journalists' social media practices, in the context of foreign correspondence, linking to one's own articles also fulfils the principle purpose of informing audiences about relevant developments within the conflict.

Traditionally, the role of disseminator casts the reporter as a detached observer who reports events as they develop. On Twitter, the shortness of the messages allows the correspondents to describe actions, motives and general moods without the need for any 'balancing' views or assessment of the broader significance of the events. However, despite their apparent neutrality, the correspondents' first and second-hand observations have an important role in Twitter's information warfare. Even when presenting only fragmented pieces of information from a narrow perspective, the disseminator effectively directs attention to particular aspects of the event and thus participates in defining what the conflict is about. In this regard, hashtags are particularly useful as they allow correspondents to insert their observations into Twitter's constantly updating stream of discussion concerning the conflict. It was found that the studied journalists preferred a small set of wellestablished hashtags, such as \#Ukraine, \#Russia, \#Odessa and \#Slovyansk for reaching as broad an audience as possible on Twitter.

One of the ways in which correspondents, in their position as neutral disseminators of information, suggest political interpretations is through the naming of the involved parties in the Ukraine conflict. Whereas the Kiev government has frequently labelled the eastern insurgents as 'terrorists' since April 2014, the Western news media have mostly settled with the apparently more neutral term 'pro-Russian separatists'. However, in the early stages of the escalation of hostilities the terms were not yet stabilised and there was considerable opposition to the usage of the "proRussian' label due to its arguable misrepresentation of the cause of the opposition and connotations 
with Russian involvement in the conflict (Ishchenko, 2014). This hotly contested ground of information warfare became evident when Mikkonen was challenged on Twitter for his use of the term 'pro-Russian'. On 3 May 2014, he posted a photo of marching citizens accompanied with a tweet: 'A procession of pro-Russians shouting honour to the heroes of \#Odessa'. A few minutes later, a Finnish magazine journalist replied to the tweet, inquiring whether it would be more apt to 'invent' a more 'descriptive' label for the protests. In a subsequent tweet, the colleague kept driving her point by offering alternative terms, including 'pro-autonomy', 'anti-Kiev' and 'pro-Eastern Ukrainian'. Mikkonen replied by acknowledging the validity of the original question but also defended his use of the term 'pro-Russian'.

This exchange highlights the highly controversial issue of naming parties in the Ukraine crisis, especially concerning the terms used in describing anti-government groups and movements (see Boyd-Barrett, 2015: 3-4). In the conditions of the information warfare of the Ukraine conflict, the apparent neutrality and 'rawness' of first-hand observations are thus challenged by the fact that all claims about reality exist in relation to the broader narratives of the conflict. When tweeting their observations from the scene, the correspondents, wittingly or unwittingly, participate in the corroboration or refutation of competing conflict narratives.

\section{The interpreter: sharing views and opinions}

In addition to sharing their first-hand observations and updates about unfolding events in the conflict, the correspondents used Twitter to post and retweet links to views, analyses and opinions from experts, other journalists and citizens. In providing followers and the Twitter public with answers to questions as to what the conflict is essentially about, which groups are driving events and what are their motives, the correspondents enacted the role of the journalist as 'interpreter' (e.g. Carpenter et al., 2015). As with the role of the disseminator, the interpretive role of the journalist does not involve explicit personal opining on the issues tweeted. However, the neutral role does not preclude mediation on the opinions of others: by linking and retweeting, journalists were able to pass along comments from other users without, at least ostensibly, accepting accountability for that message (cf. Molyneux, 2015). In the context of Twitter's information war - in which a vast range of conflicting accounts and interpretations are available, the position of journalists as interpreters boils down to questions such as whose information is passed on and which sources are endorsed. Retweeting other users' messages inevitably shapes the salience of the views and opinions circulating on the microblog; the act communicates that the view, claim or bit of information retweeted is important to take into consideration. 
Real time eyewitness tweeting, which forms the core of the war correspondents' disseminator role, is afforded by Twitter's immediacy, likewise, the role of the interpreter that is enacted primarily through retweeting and linking is supported by the platform's other main affordance: connectivity. There was, however, notable variation in how the three correspondents acted. Laurén did not retweet other users' messages and did little linking to outside sources. Instead she emphasised her own role as an analyst by linking to her own writings, many of which were columns and analyses instead of news reports. In contrast, Hakala did not promote his own reporting on Twitter but frequently retweeted opinions, assessments and views, especially from renowned international journalists with large followings on Twitter, including Howard Amos, Alec Luhn and Leonid Ragozin. Mikkonen, in turn, was an active curator and retweeter of analyses and views from a variety sources. At the same time, adapting journalistic values to the practice of tweeting, he tended to flag shared content with such headers as 'opinion' or 'point of view'. For instance, on 7 May 2014, he shared a link to a Moscow Times editorial with the following comment: 'Opinion: \#Russia's Self-Isolation by @MoscowTimes www.themoscowtimes.com/opinion/arti...”.

While sharing interpretations of others, the correspondents rarely presented their personal analyses of the events. This reluctance to adopt an authoritative position on the conflict was illustrated by Mikkonen, who was requested by a user, on 6 May, to make a personal assessment of the balance of power between the pro-Ukrainian and pro-Russian populations in Odessa. When specifically prompted, he did provide a brief evaluation in two tweets, accompanied by the caveat 'it is difficult to assess'. Yet the brief exchange with the follower underlined the overall absence of such broader evaluations and assessments in the typical tweeting practices of these correspondents.

\section{The advocate: raising public awareness and promoting an ideological position}

Much of the activity that the journalists engaged in on Twitter concerned the struggle to find reliable information about the Ukraine conflict, the effort to qualify and evaluate information and to fight against propaganda. They tweeted in response to queries about the facts they had reported and, more typically, highlighted the existence of rumours and propaganda and disqualified purportedly erroneous claims concerning events in Ukraine. The third role performed by the correspondents through tweeting, the advocate against propaganda, was thus explicitly connected to the conditions of conflict, and information warfare in particular. In terms of traditional journalistic roles, it can be seen as an extension of the advocacy role, which refers to journalists' attempts to raise awareness of a perceived problem and/or actively influence opinion formation processes among their audiences (Donsbach and Patterson, 2004; Stanham, 2007). Importantly, this role extends the political agency 
of war correspondents, allowing them to openly be actors in the conflict and have greater opportunities for focusing attention on different interpretations of events.

For example, as early reports of the clashes in Odessa circulated on 2 May 2014, indicating that a large number of anti-government activists had been killed in a fire following clashes with nationalist groups, Hakala posted the following observation: 'twitter rage \#odessa seems to be almost unanimous: \#ukraine nazis burnt 40 innocent, something must be done'. Here Hakala implicitly voiced his concern not only against one-sided interpretations, but also against attempts to present the incident in a way which would play into the preferred narrative of the Russian state media about the rise of far-right nationalist tendencies in Ukraine after the ousting of president Yanukovych. The following day, Hakala continued to fight this narrative of the Odessa incident by pointing to its apparent unlikeliness: '\#Odessa That a 5-storey Stalin era stone building would be burnt inside entirely by throwing petrol bombs from outside? \#ukraine'.

As Hakala's tweets illustrate, the correspondents' own voice is typically saturated with irony, to emphasise their 'incredulity' regarding certain interpretations of events and to discredit their presenters. Journalists' use of humour on social media and Twitter has been studied in terms of attracting the public (Holton and Lewis, 2011). Here, the use of comic devices, such as irony, is to be understood as a critique, as a way to discredit certain claims and parties to the conflict as untrustworthy and even ridiculous (cf. Glasser and Ettema, 1993). At the same time, irony typically assumes that the audience has pre-existing knowledge of events and shares the views of the speaker. Accordingly, as opposed to the ordinary news reporting that assumes the reader has little preexisting information, many of the tweets posted in the advocacy role seemed to be directed at, and aimed to build rapport with, a well-informed and like-minded audience that was capable of identifying inauthentic information and outlandish interpretations.

In this regard, it is notable that the correspondents tended to bring attention mostly to the dissemination of disinformation that supported the Russian narrative of the conflict and presented it as a major hindrance in uncovering the truth. In addition to journalists' efforts to inform readers about the complex information war, their advocacy efforts revealed an ideological anti-Russian stance. As contesting versions of events circulated in public after a fatal shooting incident in Slovyansk in April, Mikkonen retweeted a fellow journalist's assessment, which underlined just the issue: 'Pictures from \#Slovyansk indicate something did happen. Now the hard part: try to measure Right Sector stupidity vs. pro-Russian propaganda' (20 April 2014). The fact that the journalists are Moscow correspondents may partly explain their tendency to flag and ridicule specifically (proRussian disinformation. Yet their disposition reflected the broader distrust in the West of the 
claims of Russian authorities and media, amounting to a widespread perception that Russia is the primary, if not the only, party in the Ukraine conflict engaging in information warfare (Galeotti, 2015; Snegovaya, 2015). In this regard, Laurén stood out from her colleagues by also tweeting about what she saw as propaganda disseminated by the Ukraine Crisis Media Center, a news agency financed by, amongst others, George Soros, the Ukrainian government and a Ukrainian subsidiary of Weber Shandwick, one of the world's leading public relations firms. Also, by calling out, on two separate occasions, faulty claims made by a US magazine, Laurén also highlighted the untrustworthiness of some of the Western reporting on the conflict.

The community-builder: job talk and professional support

Journalists have a tendency to share daily experiences related to their work on Twitter (Lasorsa et al., 2012) and our findings suggest that job-related tweeting has a significant role in conflict reporting as well. This public 'job talk' has been argued to potentially increase journalistic transparency and to foster trust and more intimate relations between journalists and their audiences (Molyneux, 2015; Noguera Vivo, 2013). All three correspondents frequently shared their personal experiences from the field on Twitter. First of all, stationed in Moscow, the correspondents typically informed their followers when they were about to embark on a reporting trip to Ukraine, and secondly, they frequently shared their experiences of moving from one location to the next, tweeting mostly about road blocks, destroyed bridges, alternative connections, and accreditation issues.

Rather than being directed at the general audience, in the context of reporting from military conflict zones, the job-related tweets often seemed to have the purpose of tipping off, advising or warning colleagues who were possibly travelling in the area. Laurén, for instance, tweeted on 5 May 2014 about a road block: 'Roadblock about 10 kilometres from Odessa. Not a soul was guarding it, except for two friendly GAI-men (road police)'. Unusually, the tweet was written in English, instead of the usual Swedish or Finnish used by Laurén on Twitter, which indicates that she intentionally directed it to an international readership, most probably to her colleagues present in Ukraine - even though the absence of hashtags limited the likely recipients to her followers on Twitter.

In addition to alerting fellow journalists, the correspondents used Twitter for other types of interaction with colleagues. Firstly, they posted to promote other journalists' work in various ways: linking to news reports and articles and retweeting other journalists on Twitter (cf. Lawrence et al., 2014), as well as informing their followers of the presence of other Finnish reporters in Ukraine. 
Here, the use of the @ handle was indicative of the correspondents' purpose of directing users to follow their colleagues on Twitter. Secondly, the correspondents tweeted other journalists to create and strengthen personal connections. Hakala, for instance, contacted a Danish correspondent in Moscow in order to introduce himself and to thank the correspondent for a story and interview which Hakala quoted.

Thirdly, on several occasions the correspondents expressed support for their fellow journalists. It often consisted of simple wishes like 'welcome' or 'stay safe', directed at their Finnish colleagues entering the conflict zone, but it also included the retweets and reporting of international journalists who had been arrested, kidnapped or were otherwise in trouble. Finally, the correspondents entered various informal and not directly job-related exchanges with their colleagues. Indeed, it was notable that while the reporters engaged in several exchanges with nonjournalist users, they often ignored tweets directed at them by members of the public. In contrast, they practically always replied to tweets from other journalists, suggesting a practice of selective interaction on Twitter with a preference for engaging with other members of their professional community.

Job tweeting, mutual promotion and the support of other journalists suggest that the correspondents were active in using Twitter to build connections with other members of the journalistic community, especially with other war correspondents. This community builder role can be regarded as being especially afforded by social media. As Mourão (2015) notes, Twitter enhances the community-building processes of journalists as they tend to follow each other and converse personally across media outlets. Enabling the formation of a professional community may be a particularly relevant aspect of Twitter for war correspondents, who operate under extraordinary circumstances and personal threat. With their capacity for creating networks of mutual support, social media have been found to be a means for '(self-)care' by users during emergencies (Kaufmann, 2015). Accordingly, mutual support and exchanges with fellow journalists may increase the correspondents' sense of being part of a community and help them to work through their difficult and sometimes even traumatic experiences in the battlefield.

However, the community builder role directs the correspondents' attention to a limited group of sources. Reinforcing the sense of an 'interpretive community' of journalists (Zelizer, 1993), it helps them to navigate in the field of information warfare by providing them with cues on what information and which views are relevant and trustworthy. As Donsbach (2008: 66-68) has pointed out, to validate their perceptions of the relevance of an event, the accuracy of the facts and the acceptability of opinions, journalists construct a 'shared reality' with other journalists, which 
gives them the confidence to see something 'objectively' as newsworthy, true and plausible.

Accordingly, by using Twitter to communicate with their fellow reporters, war correspondents may not only direct each other's attention to events and sources of information but also validate opinions and interpretations of the events (cf. Revers, 2015: 15). Therefore, even as it potentially exposes reporters to a mountain of alternative views, interpretations, facts and disinformation, Twitter may paradoxically reinforce the creation of rather uniform interpretations of complex issues, such as the Ukraine conflict.

\section{Discussion and conclusion}

The four role enactments identified in the studied war correspondents' tweets are summarised in Table 1. Each of the roles is associated with certain tweet types and the content categories which most conveniently enable that enactment on Twitter. The fourth column lists the primary purposes the role enactments serve for correspondents in Twitter's public space. As the analysis indicates, there are several tweet types and various forms of content, i.e. alternative tweeting practices that can contribute to the enactment of each of the roles, and, correspondingly, a certain tweet type can enable the enactment of more than one role. Depending on the context, by tweeting a link to online sources, for instance, a correspondent may enact the role of the interpreter who provides analysis and context, or the connector who promotes a fellow correspondent's work, or both at the same time.

\begin{tabular}{|c|c|c|c|}
\hline Journalistic role & Primary tweet types & Relevant content & Social purposes \\
\hline Disseminator & $\begin{array}{l}\text { original content, retweet, } \\
\text { link }\end{array}$ & $\begin{array}{l}\text { first-hand observation, } \\
\text { live tweeting, quotes, } \\
\text { headlines, hashtags }\end{array}$ & $\begin{array}{l}\text { providing independent } \\
\text { and trustworthy } \\
\text { information }\end{array}$ \\
\hline Interpreter & link, retweet & $\begin{array}{l}\text { endorsements, views, } \\
\text { hashtags }\end{array}$ & $\begin{array}{l}\text { providing analysis, } \\
\text { points-of-view, context }\end{array}$ \\
\hline Adversary & original content, @ reply & $\begin{array}{l}\text { personal opinion, } \\
\text { irony, fact checking, } \\
\text { hashtags }\end{array}$ & $\begin{array}{l}\text { contesting the accounts } \\
\text { of conflicting parties, } \\
\text { flagging propaganda, } \\
\text { denouncing information }\end{array}$ \\
\hline
\end{tabular}




$\begin{array}{llll}\text { Connector } & \begin{array}{l}\text { } \text { reply, @ mention, link, job talk, support, } \\ \text { retweet }\end{array} & \begin{array}{l}\text { Communal support, } \\ \text { thanking, promotion }\end{array} & \begin{array}{l}\text { validation of } \\ \text { interpretation }\end{array}\end{array}$

Table 1. War correspondents' roles and their enactments on Twitter

The four roles analysed can be seen as adaptations of the traditional roles of journalists in a new kind of technology-mediated public communication environment characterised by instant messaging, borderless interaction and information warfare. At the same time, by blurring the lines between public and private forms of communication, Twitter often renders journalistic role enactments more transparent than those that can usually be found in their news reporting in the 'old' media (cf. Revers, 2015). The correspondents' live tweets and photos, for instance, can be compared with television reporters' live reports from the scene, and make it possible for newspaper correspondents, too, to extend their role as eyewitnesses. Sharing links to and retweeting views and analyses concerning the conflict render the role of the correspondent as an interpreter increasingly transparent, as they explicitly show some of the background information and sources of information relied on by the reporters. Similarly, discrediting disinformation and the claims of certain parties to the conflict makes it manifest to the public how the correspondents work on a daily basis to make judgments and evaluate information. Finally, expressing support to fellow reporters renders the communal nature of journalism much more evident than it is in traditional news reporting.

A prominent question regarding the adaptation of social media environments for the purposes of journalism concerns the extent to which journalists express personal opinions via Twitter and whether it points to the adoption of a more opinionated and involved role for journalists in public debate than that traditionally sanctioned by the professional norm of detachment (Lasorsa et al., 2012; Molyneux, 2015). The correspondents we analysed certainly expressed personal opinions, but they usually did so within distinct boundaries: the opinions concerned the veracity of information and aimed at discrediting propagandistic claims and did not often amount to taking an explicit stance on the conflict or declaring 'who is in the right'. Personal opinion was thus expressed well within the bounds of the traditional norm of remaining neutral observers as the literature on the 'normalization' of social media suggests (Singer 2005; Lasorsa et al., 2012). Alternatively, the reluctance of the Finnish journalists to express opinion more extensively may also reflect the fact that Twitter has been adopted by journalists in Finland more slowly than in the 
English-speaking countries (Gulyas, 2013) and suggests that Finnish correspondents are still in the process of being accustomed to Twitter's open communicative culture.

While Twitter largely enables correspondents to enact their traditional roles, the public and interactive nature of the medium means that the inherent tensions in the journalistic roles may become objects of public controversy in the context of information warfare. Even as the correspondents prefer to enact a neutral role with regard to the conflicting parties - primarily positioning themselves as impartial disseminators, interpreters and discreditors of propaganda, both members of the public and fellow journalists may question the veracity of these positions and suggest that the reporting and tweeting of the correspondents, in fact, serves particular interests in the conflict. Arguably, it is partly due to this constant threat to the self-conception of the war correspondent that the fourth role enabled by the social media, the community builder, has become so significant. By allowing the construction of a community of fellow correspondents, the war correspondents may validate their interpretations, as well as their perception of themselves as independent non-parties to the conflict, and thus be better able to cope with the potentially hostile environment of Twitter's information warfare.

Social media should be regarded as a set of unique and fruitful environments for the analysis of journalistic roles and their development. On the one hand, it enables journalists to control, to a certain degree, how they present themselves publicly. On the other hand, Twitter, in particular, allows the study of journalistic roles in a context of social interaction, which is essential to any role enactment. The four roles outlined in this study emerged as the most salient roles based on our observation, but, due to the qualitative and exploratory nature of the analysis, they should not be read as an exhaustive typology of the roles available to correspondents on Twitter. Instead, by observing how journalistic roles are enacted on Twitter, we have aimed to provide a starting point for further research on how conflict reporters adapt to and make use of social media platforms.

\section{References}

Andén-Papadopoulos K and Pantti M (2013) Re-imagining crisis reporting: Professional ideology of journalists and citizen eyewitness images. Journalism 14(7): 960-977.

Boyd-Barrett O (2015) Ukraine, mainstream media and conflict propaganda. Journalism Studies. Epub ahead of print 29 October 2015. DOI: 10.1080/1461670X.2015.1099461.

Bruns A (2012) Journalists and Twitter: how Australian news organisations adapt to a new medium. Media International Australia incorporating Culture and Policy, pp. 97-107. 
Butler J (2005) Photography, war, outrage. PMLA 120(3): 822-827.

Canter L (2015) Personalised tweeting: The emerging practices of journalists on Twitter. Digital Journalism 3(6): 888-907.

Carpenter S, Boehmer J and Fico F (2015) The measurement of journalistic role enactments: A study of organizational constraints and support in for-profit and nonprofit journalism. Journalism \& Mass Communication Quarterly. Epub ahead of print, 12 October 2015. DOI: $10.1177 / 1077699015607335$.

Donsbach W (2008) Factors behind journalists' professional behavior. In: Löffelholz M and Weaver D (eds) Global Journalism Research. Oxford: Blackwell, pp. 65-78.

Donsbach W and Patterson T (2004) Political news journalists: Partisanship, professionalism, and political roles in five countries. In: Esser F and Pfetsch B (eds) Comparing Political Communication: Theories, Cases and Challenges. Cambridge: Cambridge University Press, pp. 251-270.

European Commission. (2016, January). Humanitarian aid and civil protection, ECHO Factsheet. Available at: http://ec.europa.eu/echo/files/aid/countries/factsheets/ukraine_en.pdf

Fahy D and Nisbet MC (2011) The science journalist online: Shifting roles and emerging practices. Journalism 12(7): 778-793.

Freedman D and Thussu D (2003) War and the Media. London: Sage.

Galeotti M (2015) 'Hybrid war' and 'little green men': How it works, and how it doesn't. In: Pikulicka-Wilczewska A and Sakwa R (eds) Ukraine and Russia: People, Politics, Propaganda and Perspectives. Bristol: E-International Relations, pp. 156-164.

Glasser TL and Ettema JS (1993) When the facts don't speak for themselves: A study of the use of irony in daily journalism. Critical Studies in Mass Communication 10(4): 322-338.

Grondin D (2012) The other spaces of war: War beyond the battlefield in the war on terror. In: Grondin D (ed) War beyond the Battlefield. Abingdon: Routledge, pp. 1-27.

Gulyas A (2013) The influence of professional variables on journalists' uses and views of social media. Digital Journalism 1(2): 270-285. 
Hanitzsch T, Hanusch F, Mellado Ruiz C. Anikina M, Berganza R, Cangoz I et al. (2011) Mapping journalism cultures across nations: A comparative study of 18 countries. Journalism Studies 12(3): 273-293.

Hanusch F and Mellado C (2014) Journalism students' professional views in eight countries: The pole of motivations, education, and gender. International Journal of Communication 8: 11561173.

Hellmueller L and Mellado C (2015) Professional roles and news construction: A media sociology conceptualization of journalists' role conception and performance. Communication \& Society 28(3): 1-11.

Hermida A (2013) \#Journalism. Digital Journalism 1(3): 295-313.

Holton AE and Lewis SC (2011) Journalists, social media, and the use of humor on Twitter. Electronic Journal of Communication 21(1\&2). Available at: http://www.cios.org/EJCPUBLIC/021/1/021121.html.

Hoskins A and O’Loughlin B (2010) War and Media. Cambridge: Polity.

Hoskins A and O'Loughlin B (2011) Remediating jihad for western news audiences: The renewal of gatekeeping? Journalism, 12(2): 199-216.

Hoskins A and O'Loughlin B (2015) Arrested war: the third phase of mediatization. Information, Communication \& Society 18(11): 1320-1338.

Ishchenko V (2014) Ukraine's fractures. New Left Review 87: 7-33.

Kaufmann M (2015) Resilience 2.0: Social media use and (self-)care during the 2011 Norway attacks. Media, Culture \& Society 37(7): 972-987.

Khaldarova I and Pantti M (2016) Fake news: Struggle over news coverage of the Ukrainian conflict. Journalism Practice (in press).

Kramp L and Weichert S (2014) Covering the world in despair: A survey of German crisis reporters. Journal of War \& Culture Studies 7(1): 18-35.

Kuntsman A and Stein RL (2015) Digital Militarism: Israel's Occupation in the Social Media Age. Stanford: Stanford University Press.

Lasorsa DL, Lewis SC and Holton AE (2012) Normalizing Twitter. Journalism practice in an emerging communication space. Journalism Studies 13(1): 19-36. 
Lawrence RG, Molyneux L, Coddington M and Holton AE (2014) Tweeting conventions: Political journalists' use of Twitter to cover the 2012 presidential campaign. Journalism Studies 15(6): 789-806.

McCauley T (2015) The war of ideas on the Internet: An asymmetric conflict in which the strong become weak. Dynamics of Asymmetric Conflict 8(1): 79-90.

Maltby, Sarah; Thornham, Helen and Bennett, Daniel (2015) Capability in the digital: institutional media management and its dis/contents. Information, Communication \& Society 18(11): 12751296.

Matheson D and Allan S (2009) Digital War Reporting. Cambridge: Polity.

Mellado C (2015) Professional roles in news content. Six dimensions of journalistic role performance. Journalism Studies 16(4): 596-614.

Mellado C and Van Dalen A (2014) Between rhetoric and practice: Explaining the gap between role conception and performance in journalism. Journalism Studies 15(6): 859-878.

Meraz S and Papacharissi Z (2013) Networked gatekeeping and networked framing on \#Egypt. The International Journal of Press/Politics 18(2): 138-166.

Molyneux L (2015) What journalists retweet: Opinion, humor, and brand development on Twitter. Journalism 16(7): 920-935.

Motyl, AJ (2015) The surrealism of realism. Misreading the war in Ukraine. World Affairs, January/February. Available at: http:/www.worldaffairsjournal.org/article/surrealism-realismmisreading-war-ukraine.

Mourão RR (2015) The boys on the timeline: Political journalists' use of Twitter for building interpretive communities. Journalism 16(8): 1107-1123.

Noguera Vivo JM (2013) How open are journalists on Twitter? Trends towards the end-user journalism. Communication \& Society 26(1): 93-114.

Omanga D and Chepngetich-Omanga P (2013) Twitter and Africa's 'war on terror'. News framing and convergence in Kenya's Operation Linda Nchi. In: Olorunnisola AA and Douai A (eds) New Media Influence on Social and Political Change in Africa. Hershey: Information Science Reference, pp. 241-256. 
Papacharissi Z and De Fatima Oliveira M (2012) Affective news and networked publics: The rhythms of news storytelling on \#Egypt. Journal of Communication 62(2): 266-282.

Pikulicka-Wilczewska A and Sakwa R (eds) (2015) Ukraine and Russia: People, Politics, Propaganda and Perspectives. Bristol: E-International Relations.

Revers M (2015) The augmented newsbeat: spatial structuring in a Twitterized news ecosystem. Media, Culture \& Society 37(1): 3-18.

Sakwa R (2015) Frontline Ukraine. London: I.B. Tauris.

Snegovaya M (2015) Putin's information warfare in Ukraine. ISW Russia Report 1. Washington: Institute for the Study of War.

Statham P (2007) Journalists as commentators on European politics. Educators, partisans or ideologues? European Journal of Communication 22(4): 461-477.

Siapera E, Hunt G and Lynn T (2015) \#GazaUnderAttack: Twitter, Palestine and diffused war. Information, Communication \& Society 18(11): 1297-1319.

Singer J (2005) The political j-blogger. 'Normalizing' a new media form to fit old norms and practices. Journalism 6(2): 173-198.

Tandoc EC Jr, Hellmueller L and Vos TP (2013) Mind the gap: Between journalistic role conception and role enactment. Journalism Practice 7(5): 539-554.

Tumber H and Palmer J (2004) Media at War. London: Sage.

Tumber H and Webster F (2006) Journalists Under Fire. Information War and Journalistic Practices. London: Sage.

Vis F (2013) Twitter as a reporting tool for breaking news: Journalists tweeting the 2011 UK riots. Digital Journalism 1(1): 27-47.

Wilson A (2014) Ukraine Crisis: What it Means for the West. New Have: Yale University Press.

Zeitzoff T (2014) The way forward or just another tool in the toolbox? Social media and what it means for conflict researchers. In: Newman E and DeRouen K Jr (eds) Routledge Handbook of Civil Wars. London: Routledge, pp. 279-288.

Zelizer B (1993) Journalists as interpretive communities. Critical Studies in Mass Communication 10(3): 219-237. 
Zelizer B (2007) On "having been there": "Eyewitnessing" as a journalistic key word. Critical Studies in Media Communication 24(2): 408-428.

Zelizer B and Allan S (2011) Journalism after September 11. 2nd ed. New York: Routledge. 